\title{
O Menino, de Luiz Canabrava: o infante silenciado na periferia da cultura mineira em transformação ${ }^{1}$
}

\author{
Luiz. Canabrava's The Boy: the infant muted on the outskirts of the Mineira's culture \\ in transformation
}

Leonardo Tadeu Nogueira Palhares* Universidade Estadual de Montes Claros Montes Claros, Minas Gerais, Brasil

Ivana Ferrante Rebello** Universidade Estadual de Montes Claros Montes Claros, Minas Gerais, Brasil

\begin{abstract}
Resumo: Este trabalho pretende asseverar sobre a personagem da criança no conto "O Menino", integrante do livro Sangue de Rosaura, de Luiz Canabrava. Pretende-se fazer algumas observações sobre de que forma o menino é percebido na narrativa, o que o silêncio desta figura pode pressupor e como isto reflete em sua presença no espaço de Minas Gerais que se situa. Para isso, recorreremos a teóricos que tragam algumas percepções da infância- Maria Cristina Gouvêa (2000), Anderson Luiz Nunes da Mata (2015) - e sobre a cultura mineira - Ângela Maria Guida e Joelma Sampaio Evangelista (2005), Silvio Romero (1980) - entre outros, para fomentar nossa discussão.
\end{abstract}

Palavras-Chave: Luiz Canabrava. Representações da infância. Sangue de Rosaura.

Abstract: This work intends to assert about the character of the child in the story "O Menino" ("The Boy", in literal translation), part of the Luiz Canabrava's Sangue de Rosaura (Blood of Rosaura). Is intended to make some comments on how the child is perceived in the narrative, which the silence of this figure can be assumed and how this is reflected in its presence in Minas Gerais space is located. For this, we will use the theoretical to bring some childhood perceptions - Maria Cristina Gouvea (2000), Anderson Luiz Nunes da Mata (2015) - and about the Mineira's culture - Angela Maria Guida and Joelma Sampaio Evangelista (2005), Silvio Romero (1980) - among others, to promote this discussion.

Keywords: Childhood representations. Luiz Canabrava. Sangue de Rosaura

\section{INTRODUÇÃO}

Luiz Carlos Olivé Canabrava (1926-2000) foi um ilustrador, escritor, artista plástico e editor. Publicou, de literatura, o livro de contos Sangue de Rosaura (1954) - com tal compêndio de narrativas curtas agraciada com o Prêmio Fábio Prado um ano antes de

\footnotetext{
${ }^{1}$ O presente trabalho foi realizado com apoio da CAPES, Coordenação de Aperfeiçoamento de Pessoal de Nível Superior, CAPES - Brasil.

* Mestrando em Letras/Estudos Literários pelo Programa de Pós-Graduação em Letras/Estudos Literários da Unimontes, Montes Claros, Minas Gerais, Brasil, bolsista pela Coordenação de Aperfeiçoamento de Pessoal de Nível Superior, CAPES - Brasil. Possui graduação em Letras/Português pelo Centro de Ciências Humanas da Unimontes (2010). Email: leonardo256mega@hotmail.com.

** Doutora em Literatura Brasileira pela PUC-MG. Professora do Departamento de Comunicação e Letras da Universidade Estadual de Montes Claros-Unimontes, Montes Claros, Minas Gerais, Brasil. Email: ivanaferrante@hotmail.com.
} 
sua publicação - e o romance O Sexo Portátil (1968), além de participar de coletâneas como O Conto Fantástico (1959), organizada por Jerônimo Monteiro, e $A$ Cidade e as Ruas - Novelas Cariocas (1964), florilégio este compendiado por Ruy Carvalho. Da biografia de Canabrava encontrada, há uma reportagem publicada na Revista Pequi em 2011 por Newton Vieira. Intitulada "Luiz Canabrava: tão genial quanto esquecido", Vieira destaca a presença do artista curvelano no cenário cultural carioca em meados do século XX: por exemplo, destaca a presença de Dinah Silveira de Queiroz na vida artística do mineiro, sendo este o projetista gráfico das capas de $A$ Muralha e Eles Herdarão a Terra. A autora paulistana também escreveu a nota de orelha de Sangue de Rosaura e publicou Café da Manhã (1969) pela editora de Canabrava, a Olivé Editor (cf. VIEIRA, 2011, p. 52-57).

Sobre a produção literária de Luiz Canabrava, vemos que há breves ponderações a respeito no ensaio "A Literatura Fantástica no Brasil: alguns marcos referenciais", de Maria Cristina Batalha, a qual aponta que Sangue de Rosaura possui "contos de configuração puramente "maravilhosa"“ (cf. BATALHA in RAMOS, ALVES e HATTNHER, 2013, p. 32) e no livro $A$ Literatura Brasileira, no qual José Aderaldo Castello exemplifica Canabrava como "exemplo de contista renovador" (cf. CASTELLO, 2004, p. 469). Denilson Lopes, em breve ensaio publicado no livro Routledge International Encyclopedia of Queer Culture, ainda coloca Canabrava, junto a autores como Gasparino Damata e Aguinaldo Silva, que usam a questão do sexo - especialmente o homossexual - como imagem contra um cenário dominado pelo autoritarismo provocado pelo regime militar (cf. LOPES in GERSTNER, 2011, p. 102).

Dado este perceptível "silêncio" de estudos ao respeito de sua produção no âmbito da arte das letras, parece ser apropriado tratar de tal temática neste estudo. Para melhor asseverarmos sobre este tema, escolhemos, dentre os dez contos presentes em Sangue de Rosaura, a narrativa "O Menino", sobre um jovem a brincar no entorno de um velório de uma jovem que se suicidara. A nossa pretensão aqui, logo, é observar as possíveis implicações que o silêncio da personagem do menino no conto de Luiz Canabrava podem sugerir.

\section{2 “O MENINO” IGNORADO E RECHAÇADO}

O menino abriu caminho entre os corpos que se comprimiam a sua frente, pôs-se nas pontas dos pés e, já que a gente grande fazia o mesmo, olhou dentro do caixão.

Viu apenas um nariz fino, levemente azulado, a testa e as mãos de cera cruzadas no peito. $\mathrm{O}$ resto era um amontoado de véus brancos e flores, que rescendiam a perfume adocicado, de mistura com água-de-colônia.

Observava ainda, quando d. Jovita, de xale preto na cabeça e olhos vermelhos, baixou-se sobre ele e zangou:

- Sai daqui! Menino não pode ver essas coisas, não. Vá embora para casa.

Sentindo-se medroso e, ao mesmo tempo, importante - pela primeira vez via um morto e isto parecia-lhe uma façanha, apesar de achar que defunto devia ser mais esquisito - escapuliu 
entre as ancas gordas das donas que soluçavam e foi postar-se frente à casa, onde um pequeno aglomerado de gente esperava que o enterro saísse. (CANABRAVA, 1954, p. 109) ${ }^{4}$

Da mesma maneira que abre textualmente o conto 5 , "O Menino" é referenciado de tal forma por toda a narrativa. Não há nenhuma menção ao que possa ser o seu nome. Este tipo de tratamento pode-nos apontar para um ignorar da sua identidade e que, por consequência, acarreta na diminuição de sua existência perante aos mais adultos. A personagem da D. Jovita, a qual é devidamente nomeada, apenas irá aparecer novamente no final da história, a qual lhe configura uma participação menor.

Contudo, como poderemos observar, é a personagem do Menino que terá o centro nesta narrativa. Se pelo menos em um momento foi feita uma justiça perante os adultos de sua presença, foi com o zango de D. Jovita: o "Sai daqui!" dela fez prenunciar uma exclamação que, por opção estilística do autor, fez com que a palavra seguinte começasse em maiúscula, justamente a palavra "Menino". Embora podemos ler esta tentativa de torná-lo como nome próprio, ainda não deixa, devido ao seu significado, de carregar uma generalização que ainda leva a condizer com sua situação de ignorado perante aos adultos.

O que leva a este ignorar? A situação da narrativa trata-se de um velório. A curiosidade de um menino, um ser que mal acaba de entrar na vida, já possui um primeiro obstáculo: os "corpos que se comprimiam a sua frente". Corpo, além daqui superficialmente se referir aos adultos que cercavam o caixão, é também um termo utilizado para se referir aos cadáveres. Logo, a relação menino-vida e adulto-morte implica em um obstáculo deste na vida daquele. O adulto, associado à morte, é o que "talha" a cultura da criança, a gritar com ela, impedí-la de ver o corpo da falecida.

Não é permitido, ao menino, ter a experiência sinestésica com o corpo: a visão das cores azul e branca e pressupor o tato do nariz fino, das mãos e da testa de cera; o cheiro do "perfume adocicado, de mistura com água-de-colônia". Ante a figura aterrorizadora de d. Jovita, "de xale preto na cabeça e olhos vermelhos", tal qual um "corpo" adulto que resplandece a questão da morte, ela o afasta ao zango. Porém, o menino, a vida, se vinga: embora flertara com o medo, sentiu-se importante ao ver um defunto. É a vingança da criança, cuja cultura adulta o considera "despreparado" para enxergar tamanha realidade.

\footnotetext{
${ }^{4}$ Como a obra é datada de 1954, ainda conserva algumas peculiaridades dos acordos ortográficos da época, como a acentuação de "cêra" e "prêto". Optamos aqui, e nas demais citações do conto, por atualizar a grafia, a qual não causa nenhum prejuízo no entendimento da obra. Contudo, como não há registros de reedições posteriores, complementamos essa nota no que tange a falta de interesse que a literatura de Luiz Canabrava teve por décadas e que aqui, independentemente dos juízos que colhemos, traga alguns apontamentos a este escritor tão pouco estudado.

${ }^{5}$ Textualmente digamos, pois o conto inicia-se com uma ilustração do próprio autor a respeito do conto. Todas as narrativas de Sangue de Rosaura são antecedidas com um desenho de autoria de Canabrava. Dada a nossa pretensão de analisar a personagem do menino apenas na parte textual em si, pretendemos focar nas ilustrações em uma análise futura.
} 
Todavia, deve-se observar que quem incita a percepção deste ato é o narrador: é ele quem narra o menino e, além de percebermos esta subjulgo do personagem ante ao narrador, há também a questão de que o menino, que é, igual aos outros personagens, à mercê do narrador que orienta e seduz o leitor no que tange aos seus atos, levado a ter pouco espaço na narrativa em virtude de sabermos quem é a defunta, e o que com ela aconteceu:

Eram três horas de uma tarde indecisa entre o sol e um chuvisco de verão. Os trovões ameaçavam fracamente, ao longe. O dobrar triste do sino da Matriz percutia no ar parado, avisando que estava prestes a sair o corpo de Angélica, a última das três filhas de d. Teutônia. O menino estivera caçando passarinhos, mas conseguira apenas um espinho na sola do pé.

Sentou-se na beira da calçada, mexeu na pele grossa e suja, inutilmente. Depois, levantou-se e sugou um catarro aborrecido.

Já não pensava no pé ferido, quando arrumou os suspensórios de pano da calça de mescla. Prestava atenção no que dizia seu Isidro, no meio de um grupo de homens engravatados, que esperava ali fora, por estar cheia a sala.

Seu Isidro era magro, escuro e comprido como o guarda-chuva amarradinho no qual se apoiava.

- É a terceira das meninas de d. Teutônia que se vai, a última! - mumurrava ele, compungido, debaixo dos longos bigodes esbranquiçados. - Todas do mesmo jeito. A primeira foi Amália. Você se lembra dela, Pedro? Não, não deve se lembrar mesmo, não era do seu tempo. Isto foi há uns dez anos atrás. O mais esquisito de tudo é que nenhuma delas tinha motivo aparente, nenhuma deixou explicação. Foram as três quase na mesma idade. Etelvina devia ter uns trinta e quatro; Angélica, pelos meus cálculos, não passava dos vinte e oito. (CANABRAVA, 1954, p. 110).

Desta página inteira do livro, apenas três parágrafos correspondem uma atenção à figura do menino. Os demais, que são mais extensos e ocupam boa parte da aula, remetem-se ao velório da adulta. Aqui, inclusive, consta a fala de um personagem: seu Isidro, o qual explicita mais detalhes a vida da defunta. A história do cadáver, apesar do título da narrativa se referir ao menino, é que é focalizada pelo narrador: este guia a percepção da criança completamente ignorada pela cultura adulta, ainda mais em um momento considerado como importante para eles, uma vez que estavam todos reunidos para velar o corpo da filha de d. Teutônia, Angélica.

Os três curtos parágrafos dedicados ao menino apontam três instantes de sua situação: o seu ferir, o seu aborrecer, e a sua escuta dos adultos a narrarem o fato. $\mathrm{O}$ menino, o urgir da flor da vida, não tem as suas angústias simplesmente relegadas pelo adulto: o narrador insere as passagens do menino como se elas fossem anômalas ao restante da narrativa, que foca-se, com mais atenção e com espaço à voz dos adultos. $\mathrm{O}$ menino-vida, sem direito à fala, fere-se e aborrece-se com a dor, enquanto que os adultos estão mais preocupados em arguir sobre o que já morreu do que a respeito do que ainda mal sabe o que é, mas representa a vida.

Maria Cristina Gouvêa, em seu texto "A Construção do 'Infantil' na Literatura Brasileira" aponta que o que caracteriza a natureza infantil, especialmente na literatura do começo do século XX, é a relação da criança "à atividade (mais exatamente à atividade física) que tem no brincar sua maior expressão.” (GOUVÊA, 2000, p. 4). Parece que isto 
se apresenta neste conto em estudo: o brincar do menino é o seu exercer da vivência da vida. A traquinagem de caçar passarinhos, de tirar "a liberdade", ou "a vida" deles mesmos, soa-lhe como algo natural. A morte aqui lhe é corriqueira. Porém, a morte de um adulto é que quebra o seu desejo de brinquedo: a atenção que o velório o traz rompe completamente com o seu ser de criança, e o aproxima de um espaço o qual deverá se portar em seu futuro, que é a cultura adulta.

Mas que morte é essa, que toma espaço de destaque na narrativa inteira? A filha de d. Teutônia, Angélica, assim como as suas duas irmãs Amália e Etelvina, se suicidou mais ou menos com a mesma idade, conforme a longa fala de seu Isidro, que tem espaço nesta narrativa, nos disse na citação acima, e que tal discussão repercute:

- Isto também não, seu Isidro! - aparteou um homem gordo e baixo. - Vinte e oito tenho eu e, desde que me entendo por gente, que Angélica já era a mesma coisa. Ainda ontem ela esteve lá na loja. Estava acabada, sorumbática , comprou uma dúzia de botões de madrepérola e um carretel de linha. Quando tirou o dinheiro da bolsa, estava tremendo tanto, que deixou cair uns trocados, parecia tonta, vexada. Isto foi ontem de manhã. Certeza absoluta de que ela tinha mais de trinta e três.

- Dois trinta é que não passava. Engraçado, que motivo teria ela? Até que era bonita. Você viu agora como está?

Um rapaz aproximara-se do grupo, curioso, de mansinho. Via-se que não estava perfeitamente inteirado da morte de Angélica.

- Ouvi falar que ela se suicidou no banheiro. Como é que foi, seu Isidro?

- Não sei direito, não. Me contaram que foi na corda da descarga da privada. D. Teutônia achou-a, de manhãzinha, com a língua de fora.

- D. Teutônia é uma mártir. Que gente de urucubaca!

- É verdade que é a terceira que faz a mesma coisa?

- É - continuou seu Isidro, bem informado. - Da Amália andaram falando que tinha sido receita errada que o farmacêutico aviara . Qual nada! Ela tinha tomado formicida. Uma pena, bonita de dar gosto ! Dizem que estava apaixonada por um homem casado, um tal de Fernandão, que logo depois se mudou daqui com a família. (CANABRAVA, 1954, p. 111112).

A página seguinte, assim como a terminação de seu último parágrafo na próxima, não mencionam sequer o menino em detrimento da discussão não apenas da defunta, mas também da idade a qual ela teria morrido, e os motivos que levou ela e a irmã Amália a terem suicidado. Para uma narrativa cujo título trazia uma expectativa sobre o que seria abordado no conto, soa como anticlimático ter, das cinco páginas textuais as quais competem este conto, uma inteira dedicada a uma história que não tem nada a ver com a criança. Não que ela seja totalmente omitida: tal narração dentro da história apenas é desencadeada por causa do escutar que a criança, em seu silêncio, se permite ouvir a respeito da situação.

Assim, podemos abordar que uma história dentro da ficção é a responsável por levar o menino ao silêncio. A cultura adulta, primeiramente a negar, na figura de d. Jovita, o menino a ver a morta, agora sustenta o seu silêncio com base de uma história de alguém que, numa situação tão trágica, seria mais interessante do que o título da história propõe a contar. E é uma história pautada por breves momentos de suposições: há divergências 
sobre a idade e a fisionomia da filha de d. Teutônia, e o tom que pedem ao seu Isidro que conte a história do suicídio possuí um tom quase que anedótico, de curiosidade a respeito de tamanho fato picante.

Como o narrador não confirma as histórias relatadas pelos personagens, podemos pensar que tais relatos orais carregam traços que podem ser depurados como duvidosos, quase que ficcionais. Assim, temos aqui a presença de duas narrativas que prensam o menino em seu silêncio: uma, que é o conto em estudo, o qual é o narrador que se sobrepõe as ações do menino e o narra sem dar espaço, assim como aos demais, para ter seu momento de voz; e a dentro da história, que leva a criança ao silêncio em nome da curiosidade de saber tudo o que acontecia naquele velório.

Anderson Luis Nunes da Mata, em seu texto "Infância na literatura brasileira contemporânea: tema, conceito, poética”, percebe que o narrador entra, por vezes, como representante da voz infantil para superar um silêncio através da memória ou observação (cf. MATA, 2015). Quer dizer, embora o narrador ainda seja uma força que conduz o menino pela narrativa, de modo a não lhe dar falas, ele também é o seu representante sobre o ignorar que lhe acontece em meio ao velório. $\mathrm{O}$ narrador supera o silêncio da criança ao colocá-la não apenas como título do conto, mas também por lhe dar atenção em momentos alternados, de forma a destoar da história de Angélica, a qual é a que tem mais atenção por toda a narrativa.

O que poderia ser ressaltado desta discussão? Propomos algo que, assim como o menino, é silenciado nesta narrativa dentro do livro Sangue de Rosaura: a presença de Minas Gerais.

\section{MINAIS GERAIS: OCULTA, NEGADA, SILENCIADA}

Para entender melhor a nossa pressuposição, deve-se entender que a leitura feita aqui de "O Menino" integra uma leitura geral que propomos como dissertação de mestrado a ser feita em Sangue de Rosaura. Esta discussão, por ser longa, não será totalmente apontada aqui. Mas a nossa intenção é ver, nos dez contos de Luiz Canabrava, o retratar de uma Minas Gerais estereotipada e que, em algumas narrativas, é mal referenciada ou nem mesmo explicitada, como uma forma de silenciar e relegar este estado em uma posição de decadência e emudecimento na história.

Silvio Romero, ao falar sobre a "Escola Mineira" em seu História da Literatura Brasileira, acaba por fazer algumas considerações, mesmo que indiretas, sobre o se portar do mineiro: chama Basílio da Gama de [...] "tipo de mineiro fleumático, anedótico, desconfiado e corajoso.” (ROMERO, 1980, p. 418). De Cláudio Manuel da Costa, diz-se que "[e]le era tímido, recatado, melancólico, ainda que aparentasse essa bonomia mineira, que se manifesta em pilhérias e chufas inofensivas". (ROMERO, 1980, p. 448). O mineiro, de acordo com Silvio Romero, suspeitaria de qualquer coisa que o cercasse e, embora tranquilo, estaria sempre desconfiado. Este parece ser o tom da conversa dos personagens adultos: tranquilos em respeito à figura da defunta, tramam desconfiados tudo o que a cerca, como se até mesmo a idade fosse motivo para peleja verbal. O menino, contudo, passa inerte à isso no começo da narrativa: ele brinca com o bodoque, porém, após o 
safanão de d. Jovita por querer espionar o caixão, aquieta-se. Sofre uma repreensão que o faz a agir" como um bom mineiro", calado, quieto, a escutar os outros e a "absorver suas tradições" sem direito a voz.

O menino, silenciado, é como se fosse o fruto dessa tradição mineira de ser calado: o silêncio era um aprendizado de que sua palavra não deveria ecoar entre as Minas. Ante a isso, propomos que, nesta narrativa, Minas Gerais seria uma alusão à d. Teutônia, e o seu fracasso no que tange as três filhas: tanto ela quanto as rebentas, todas mulheres, simbolizariam um sinal de esperança de que a cultura mineira perpetuasse. Porém as três filhas, com o suicídio, ou seja, com o autointerromper da própria vida, não só levam à desgraçada da mãe, como devidamente ponderados pelos senhores que discutiam a respeito, como também é a quebra da possível continuidade da tradição mineira, através da figura feminina que pode representar a fertilidade.

O falecimento de Angélica é pela corda da privada, aquilo que leva os dejetos humanos embora. O que não é bom ou excessivo para o nosso corpo é eliminado junto com as fezes. A sensação de ser filha de Minas Gerais, de uma terra ainda arraigada às tradições, é demais para ela: sente-se inútil e, mesmo com o dom da fertilidade, acha-se incapaz de superar os anseios de sua matriarca. Já morte de Amália, dita por seu Isidro por formicida, alude a este remédio que mata um pequeno animal trabalhador que vive na terra. O rompimento desta produtividade é o primeiro indício do interromper de um possível ciclo de sustentação da tradição. Atentemos a página seguinte:

O menino, nesse instante, ajeitava a atiradeira no bolso traseiro. Em seguida, apertou o próprio pescoço, contornando-o com as duas mãozinhas, pôs a língua de fora e fechou os olhos. A brincadeira, porém, fê-lo tossir e fungar e, novamente, voltou a atentar na conversa de seu Isidro.

- A Etelvina usou a espingarda do falecido Abelardo. Não faz nem uns quatro anos. - Seu Isidro acendeu um cigarro de palha. - Você está lembrado dela, Tião? Aquela sim, era nervosa, arredia, nem foi de admirar.

- D. Teutônia agora está sozinha - penalizou-se o gordo. - Quem sofre mesmo é ela. Será que vai ter coragem de continuar morando nessa casa amaldiçoada?

Olharam todos para a casinhola baixa, de meio-fio lajeado. Tinha quatro janelas na frente e uma escadinha de três degraus, que levava à cancela pintada de verde da porta de entrada.

- Olha. Acho que está na hora. O enterro foi marcado para as quatro

- Ouvi falar que gente que se mata não pode ser enterrada em campo santo.

- A rigor tem que ser assim. Mas o vigário não leva essas coisas ao pé da letra, não. Você não ouviu o sino dobrando? O que ele não vai fazer, mesmo, é rezar o ofício dos mortos. Acho que ele age direito, sabe-se lá o que passava na cabeça da pobre coitada? Quem é que pode pôr culpa nela? (CANABRAVA, 1954, p. 112-113).

O menino volta a ter espaço, mesmo que por um breve instante. Percebe-se que ele tenta se enforcar tal qual Angélica, a se sufocar. Podemos pensar que a criança entendeu que, se também se matasse tal qual ela, iria conquistar a mesma importância que ela tinha naquele momento para com os adultos. A criança vê que, se fizer a mesma coisa que a adulta, terá reconhecimento, e não será mais ignorado ou mal tratado. Trata-se, portanto, de um defeito da tradição que, mal interpretado pela criança, a leva a cometer atos que traduzem como um ensino feito de forma relegada, como se ela, apenas pelo 
mero contato com o meio, fosse absorver a cultura local e, assim, aprendesse "o que deveria ser aprendido".

Esse perceber do menino que deveria se matar para ter importância é um destaque de dentro da narrativa: até mesmo na própria história em que ele leva como título o seu destaque é relegado em nome de um cadáver adulto. Também sabemos o motivo do suicídio de Etelvina: com um tiro de espingarda. O "falecido Abelardo", embora não seja esclarecido na narrativa, mas pode ser sugerido como o patriarca desta família de filhas suicidas, pode reforçar a ideia dos responsáveis da prole como indutores do ato das moças em tirarem a própria vida. É o negar de que pertence a uma geração e que vai continuála. Seu Isidro, no entanto, parece querer relevar isso, ao considerá-la como nervosa e arredia, como se isso diminuísse uma possível culpa dos progenitores pelas atitudes ${ }^{6}$.

Um destaque para o trecho dessa narrativa é o momento em que indagam se vão enterrar Angélica "em um campo santo", por ela ser suicida. Ao afirmar que o vigário "não leva essas coisas ao pé da letra", podemos observar que há uma rendição da tradição em favor de um caso em específico. A morte da filha de d. Teutônia pode significar uma quebra de várias tradições: as das filhas que morrem primeiro que os pais e os suicidas a serem aceitos nos campos santos. As inférteis filhas de Minas Gerais, ao se matarem, colaboram para essa transformação da cultura mineira, a qual o menino, sem pai, nem mãe, a assistir a tudo calado, vê como um mero espectador na narrativa que deveria ser dele.

No texto "De Minas para o Mundo", Ângela Maria Guida e Joelma Sampaio Evangelista discorrem sobre o que poderia ser relacionado a cultura mineira. A se apoiarem no conceito de identidades de Stuart Hall, apontam "a tradicional família mineira", "a religiosidade fervorosa", "a educação severa", "culinária simples" entre outros como elementos pertencentes à esta cultura, como construções discursivas; e que em um tempo que se discute a descentralização do sujeito, discursos fragmentados e crises de identidades, parece incoerente preservar uma tradição mineira (cf. GUIDA e EVANGELISTA, 2005, p. 3). Um dos temas tratado no conto, a questão da religiosidade, parece ser associada com o que diz no que tange à essa tentativa de preservação da tradição mineira em tempos de novo olhar sobre as culturas. O que adianta tentar impor a um menino uma cultura, se ele pode ter outros anseios?

O conto se encerra com o cortejo. Ao menino, mais uma vez, é dedicado poucos parágrafos do narrador, bem como um ignorar a continuar a ser feito pelos adultos:

$\mathrm{Na}$ porta da casa houve um movimento de gente se afastando, para dar passagem ao caixão de virgem.

Duas ou três mulheres, que havia conhecido Angélica mais de perto, choravam alto.

\footnotetext{
${ }^{6}$ Isto pode também aludir a uma percepção de machismo no conto, por causa dessa visão "histérica" da mulher, bem como há narrativas em Sangue de Rosaura, como "O Buraco", cuja questão pode ser discutia a ter este livro de Luiz Canabrava como corpus. Contudo, não abordaremos este tema tanto neste estudo como na nossa dissertação, o que fica em aberto para pesquisas futuras sobre a coletânea de contos do referido autor.
} 
Logo atrás, apareceu uma velha magrinha e lívida, amparada por d. Jovita. Estava com a cabeça semi-caida para trás, movia-se com passos de sonâmbula, como se também fosse morta e a obrigassem a andar. Não tinha lágrimas, nem gritos, nem culpas. Era d. Teutônia. O menino foi empurrado e ficou espiando de longe.

Passaram mulheres soluçando baixo, homens, moças carregadas de flores. O grupo de seu Isidro acompanhou-os, por fim, lentamente.

O menino enfiou a mão no bolso traseiro para se certificar de que a atiradeira ainda se encontrava ali.

O enterro ia dobrando a esquina, no silêncio da rua empoeirada, onde brilhava o pouco de sol que conseguira varar as nuvens.

Tossiu, limpou o nariz na manga da camisa e, mancando, seguiu atrás. (CANABRAVA, 1954, p. 113)

No final, o menino volta a ter protagonismo no conto que leva o seu título, ainda assim relegado na história, a ser obrigado a seguir, por último, o cortejo fúnebre dos adultos a levarem o corpo de Angélica. O menino, sem pai e nem mãe, pode ser visto como o nascido em Minas Gerais, mas que não se identifica como o mineiro. A esta cultura, repleta de velhos já resignados com a sua transformação em tons decadentes, merece a sua atenção para observar algo que acha pitoresco, porém que, assim como qualquer cultura adulta, priva-o do direito de ter a curiosidade plena de saber do que se trata, e ainda mais: toma-lhe o espaço narrativo, a levá-lo a escutar sobre o que se trata do que ter maior participação sobre os fatos que ocorrem.

\section{CONSIDERAÇÕES FINAIS}

O conto "O Menino", de Luiz Canabrava, nos apresenta uma narrativa em que a criança não é apenas ignorada pelos adultos, mas também pela própria estrutura do texto, quando o narrador dá espaço a história da suicida Angélica ao invés do próprio menino o qual assim se intitula a narrativa. Tal percepção, contudo, serve para demonstrar a decadência da cultura mineira, se pensarmos o livro Sangue de Rosaura como uma coletânea de narrativas os quais trazem a temática de Minas Gerais, explícita ou não, a decair. Os narradores dos contos do livro de Luiz Canabrava teriam semelhante propósito ao do conterrâneo do autor, Lúcio Cardoso que, assim trago por André Seffrin, nos diz que seu propósito com Crônica da Casa Assassinada é

[m]eu movimento de luta, aquilo que viso destruir e incendiar pela visão de uma paisagem apocalíptica e sem remissão é Minas Gerais. Meu inimigo é Minas Gerais. O punhal que levanto, com a aprovação ou não de quem quer que seja, é contra Minas Gerais. Que me entendam bem: Contra a família mineira. Contra a literatura mineira. Contra o jesuitismo mineiro. Contra a religião mineira. Contra a concepção de vida mineira. Contra a fábula mineira. (CARDOSO, 2008, p. 9).

Parece ser a mesma coisa que vemos no conto "O Menino", porém com um ressaltar: não há qualquer menção, mesmo que por alguma referência cultural típica, que possa referenciar Minas Gerais superficialmente neste conto. E isto nos parece ser a intenção do narrador: ocultar Minas Gerais, silenciar esta cultura, e ao mesmo tempo 
mostrar as filhas infrutíferas que ela gera é uma vingança ao menino, o qual sofreu silenciamento em detrimento desta cultura que, por atos como o enterro da suicida em campo santo, mostra a sua transformação e, em consequência disso, sua decadência. Não dizer o nome de Minas Gerais é a vingança por não querem saber do menino, muito menos o seu nome, ante aos adultos nomeados que se suicidam por não suportarem o fardo de carregarem a própria cultura.

\section{REFERÊNCIAS}

BATALHA, Maria Cristina. "A Literatura Fantástica no Brasil: alguns marcos referenciais". IN: RAMOS, Maria Celeste Tommasello. ALVES, Maria Claudia Rodrigues. HATTNHER, Alvaro Luiz (orgs.). Pelas veredas do fantástico, do mítico e do maravilhoso. 1. ed. São Paulo: Cultura Acadêmica; São José do Rio Preto, SP: HN, 2013.

CANABRAVA, Luiz. Sangue de Rosaura. Rio de Janeiro: José Olympio, 1954

CARDOSO, Lúcio. Crônica da Casa Assassinada. $7^{\mathrm{a}}$ ed. Rio de Janeiro: Civilização Brasileira, 2008.

CASTELLO, José Aderaldo. A Literatura Brasileira: origens e unidade (1500-1960). São Paulo: Edusp, 2004

GOUVÊA, Maria Cristina. “A Construção do 'Infantil' na Literatura Brasileira". Disponível em: http://goo.gl/FlJE5D. Acesso: 10-04-2016 14h02min

GUIDA, Ângela Maria. EVANGELISTA, Joelma Sampaio. "De Minas para o Mundo". IN: Revista Virtú, Segunda Edição - Especial, Anais do III Simpósio de Formação de Professores de Juiz de Fora. Juiz de Fora: UFJF/ICH, 2005. Disponível em: http:/ / www.ufff.br/virtu/files/2010/04/artigo-2a37.pdf. Acesso: 24-04-2016 16h50min

LOPES, Denilson. "Brazil, Literature”. IN: GERSTNER, David A. Routledge International Encyclopedia of Queer Culture. New York, NY: Routledge, 2011.

MATA, Anderson Luis Nunes da. "Infância na literatura brasileira contemporânea: tema, conceito, poética”. Disponível em: http://goo.gl/zbQGRr. Acesso: 10-04-2016 $14 \mathrm{~h} 03 \mathrm{~min}$.

ROMERO, Silvio. História da Literatura Brasileira. $7^{\mathrm{a}}$ ed. Rio de Janeiro: J. Olympio. Brasília: INL, 1980.

VIEIRA, Newton. "Luiz Canabrava: tão genial quanto esquecido". Pequi Magazine. Curvelo, v. 4, n. 5, 2011, p. 52-57.

Recebido em: 05/06/2018

Aprovado em: 23/07/2018

Publicado em: 01/12/2018 